\title{
BMJ Open The impact of the asylum process on mental health: a longitudinal study of unaccompanied refugee minors in Norway
}

Marianne Jakobsen, ${ }^{1}$ Melinda Ashley Meyer DeMott, ${ }^{1}$ Tore Wentzel-Larsen, ${ }^{1,2}$ Trond Heir ${ }^{1,3}$

To cite: Jakobsen M, Meyer DeMott MA, Wentzel-Larsen T, et al. The impact of the asylum process on mental health: a longitudinal study of unaccompanied refugee minors in Norway. BMJ Open 2017;7:e015157. doi:10.1136/ bmjopen-2016-015157

- Prepublication history for this paper is available online. To view these files please visit the journal online (http://dx.doi. org/10.1136/bmjopen-2016015157).

Received 17 November 2016 Revised 8 May 2017 Accepted 16 May 2017

\section{CrossMark}

${ }^{1}$ Norwegian Centre for Violence and Traumatic Stress Studies, Oslo, Norway

${ }^{2}$ Regional Center for Child and Adolescent Mental Health,

Eastern and Southern Norway, Oslo, Norway

${ }^{3}$ Faculty of Medicine, Institute of Clinical Medicine, University of 0slo, Oslo, Norway

Correspondence to

Dr Marianne Jakobsen;

marianne.jakobsen@nkvts.no

\section{ABSTRACT}

Objectives To examine the mental health of unaccompanied refugee minors prospectively during the asylum-seeking process, with a focus on specific stages in the asylum process, such as age assessment, placement in a supportive or non-supportive facility and final decision on the asylum applications.

Design This was a2 $\frac{1}{2}$ year follow-up study of unaccompanied minors (UM) seeking asylum in Norway. Data were collected within three weeks $(n=138)$ and at 4 months ( $n=101), 15$ months $(n=84)$ and 26 months $(n=69)$ after arrival.

Setting Initially in an observation and orientation centre for unaccompanied asylum-seeking adolescents, and subsequently wherever the UM were located in other refugee facilities in Norway.

Participants Male UM from Afghanistan, Somalia, Algeria and Iran.

Main outcome measures Mental health symptoms assessed by Hopkins Symptom Checklist-25 and Harvard Trauma Questionnaire.

Results At the group level, the young asylum seekers reported high levels of psychological distress on arrival and symptom levels that stayed relatively unchanged over time. According to age-assessment procedures, $56 \%$ of the population were not recognised as minors. Subsequent placement in a low-support facility was associated with higher levels of psychological distress in the follow-up period. Those who were placed in a reception centre for adults had higher levels of psychological distress symptoms both after 15 months and 26 months compared with the remaining participants who were placed in reception centres for youth. Refusal of asylum was highly associated with higher levels of psychological distress. Conclusion Mental health trajectory of young asylum seekers appears to be negatively affected by low support and refusal of asylum.

\section{INTRODUCTION}

In 2015, more than 88700 unaccompanied minors (UMs) fled to Europe, ${ }^{1}$ putting considerable pressure on these countries to provide the necessary resources needed. Separated children who are no longer protected by parents or other caregivers, usually have to be

\section{Strengths and limitations of this study}

- Strengths include a longitudinal design, with first assessment within 3 weeks after arrival to the host country, and repeated measures.

- Use of computer-based assessment with audiotranslations throughout the study.

- Selection of participants was limited to the most common nationality groups arriving in Norway at the time of inclusion.

- High attrition rate due to the fact that asylum seekers tend to move between and within countries and that many were told to leave the country.

under the age of 18 in order to be given the special protection and care that is granted unaccompanied refugee minors. In the countries of origin for UM, the civil registration service of their country often function poorly, and birth certificates can be lost, thrown away or falsified. ${ }^{2}$ The scientific basis for assessing age is controversial, in that these tests only determine physical maturity and are most uncertain from the age of 15 to 21 years, where natural variation is at its greatest. ${ }^{3}$ The consequences for many young asylum seekers assessed to be 18 years or older is that they will no longer be considered as minors and therefore not receive special protection in accordance with the United Nations. ${ }^{2}$

Most studies investigating UM mental health have a cross-sectional design with a selection of youths with different levels of legal recognition and different durations of time in exile. ${ }^{4}$ These studies show consistently that individual factors such as exposure to violence and other traumatic events prior to migration, correspond to elevated symptoms of psychological distress. ${ }^{5}$ In some studies, the negative effects of exile-related stressors are also described, ${ }^{6}$ yet they focus on youths with varying time in exile. There are different 
asylum procedures within the different countries, ${ }^{7}$ and most UM endure some uncertainty before their legal status is defined. Most countries provide some form of shelter for UM while they are waiting for their case to be processed, but conditions vary greatly. Positive health effects have been shown to be associated with receiving a permanent residence permit, ${ }^{8}$ but this process may take months and sometimes years. The impact of different levels of social support that UM are offered, especially after the first stage of reception and registration, has not been studied in detail. ${ }^{9}$

The aim of our study was to examine UM's mental health during the asylum-seeking process and more specifically whether the official age assessed, level of support and the outcome of the asylum application were associated with UM's mental health at different stages of the asylum-seeking process.

\section{METHODS}

\section{Participants and procedures}

The sample in this study was recruited from an asylum reception centre for unaccompanied asylum-seeking adolescents between ages 15 and 18 years, which was the only one in Norway at this time. In this reception centre, all UMs who claimed to be in this age group stayed for the first weeks while asylum interviews and age-assessment procedures were performed. A research assistant kept track of all new arrivals, and each time our testing capacity allowed us to include some new participants, she was instructed to invite the ones who had arrived most recently. The study was conducted between September 2009 and March 2011. Altogether, the inclusion periods for this project were 12 weeks in 2009, 8 weeks in 2010 and 21 weeks in 2011. During these time periods, young asylum seekers came mainly from Afghanistan and Somalia. According to the statistics unit at the Norwegian Directorate of Immigration, 406 male UM from these language groups arrived in Norway during the inclusion periods. Unaccompanied males who had just arrived were contacted by the research assistant. Altogether, 216 adolescents were asked to participate, and 209 returned the informed consent and attended the study. Some participants were included in an Expressive Arts intervention group $(n=71)$ that is not part of the present study. The remaining 138 are the focus of this article. Inclusion in the intervention group was based on a randomising procedure shortly after arrival in Norway. The participants in the present article were not significantly different from the intervention group in any baseline characteristics $(p \geq 0.071)$.

More about the whole project can be found on our home pages. ${ }^{10}$

Information to participants included statements that participation would not impact the chances to stay in the country. Only one contact attempt was made for each individual, and no payment was offered.
Participants followed the normal procedures in the asylum process. In Norway, all UMs receive assistance from a multidisciplinary professional staff (educators, social workers, psychologists, physicians and nurses) in the first reception centre while waiting for their 'official-age' to be assigned. Those defined as 18 or older can be moved to adult housing where less professional assistance is provided. The asylum seekers considered to be from 15 to 18 years are moved to specialised youth centres, with staff available 24 hours, every day. The youngest children stay in even more specialised orphanages. There are some exceptions to this pattern; according to variable housing capacity, some 18-year-old asylum seekers are allowed to stay in the youth centres for some time. The youth centres are located all over Norway and have language classes for all inhabitants. Food is prepared and served by the staff, and there are staff members available day and night. Most centres have recreational activities, and they give individualised support and medical follow-up if needed. In an adult centre, the asylum seekers are left to themselves most of the time. They buy and cook their own food, have no school or other scheduled activities and have no guardians or staff members to ask for advice.

The first screening procedure was conducted within the first 3 weeks and later repeated at 4 months $(n=101), 15$ months $(n=84)$ and 26 months $(n=69)$ after arrival. At the last assessment, the population was almost halved, mainly because many of the informants were transported out of the country or had disappeared from the different living facilities. The participants who were deported were mostly individuals who had been registered as asylum seekers in another European country before coming to Norway or individuals suspected of having some connection to illegal activities. The ones who deflected were typically those who feared deportation after their asylum applications were turned down. It was, however, impossible to obtain exact numbers and reasons for the attrition in this project. When we compared those who have completed all four assessments with those who missed out at one occasion or more, there were no significant differences in any baseline demographic or symptom variables.

\section{Measures}

Demographic data were registered with the aid of interpreters at the initial assessment. We asked for self-reported age, literacy, years of school attendance and whether their parents were still alive, deceased or if participants had lost touch with their parents and did not know. Later, we registered the results of official age assessments, especially which participants who were thought to be at least 18 years of age. We also determined the level of care offered according to placement in asylum centres for either adults or for youth. Before the last assessment, we registered the legal status, as participants were either given time-limited or permanent permission to stay or were refused legal residence in the country. New variables of interest such as level of care and legal status were included when they occurred prior to a new assessment. 


\section{Exposure}

Serious Life Events checklist (SLE) was developed by Tammy Bean and colleagues ${ }^{11}$ in order to assess if an adolescent meet the criteria A1 (experienced a traumatic event) in the Diagnostic and Statistical Manual of Mental Disorders, Fourth edition (DSM-IV), for a diagnosis of post-traumatic stress disorder (PTSD). It is a self-report questionnaire which asks whether or not the participant has experienced 12 different kinds of traumatic events, such as separation from family, natural disaster, war and physical or sexual abuse. The instrument was scored by answering yes or no on each item.

\section{Psychological distress}

Hopkins Symptom Checklist-25 (HSCL-25) ${ }^{12}$ is a self-administered questionnaire designed to measure anxiety and depression. It has been validated in various clinical and community samples. ${ }^{13} 14$ The HSCL-37 A version is an extension of the HSCL-25 and has also been applied in a number of refugee studies with minors. ${ }^{15} 16$ The additional 12 items measuring externalising behaviour are not included in this paper. Each item was scored with 1 (not bothered) to 4 (extremely bothered). Scores $\geq 2$ was considered probably clinically significant. ${ }^{17}$

\section{Post-Traumatic Symptom Score (PTSS)}

The Harvard Trauma Questionnaire ${ }^{18}$ (HTQ) is a comprehensive instrument that was developed to assess potentially traumatic experiences and post-traumatic symptoms in various cultural contexts. Its psychometric properties were first established in a highly traumatised, clinical population, but it has also been evaluated with a larger community sample and with asylum-seeking adolescents. ${ }^{619}$ The HTQ part IV comprises 30 symptom items, among which the first 16 items measure 'The symptoms of PTSD' according to the DSM-IV. ${ }^{20}$ These 16 items are scored with 1 (not at all) to 4 (extremely). Scores $\geq 2$ was considered probably clinically significant. ${ }^{17}$

\section{Computer-based assessment}

The chosen psychometric measurements were combined into a single questionnaire using the program MultiCASI. $^{21}$ The questionnaires were filled in by the participants themselves, in their native languages, Dari, Pashto, Farsi or Somali, using laptops with touch-screen function. Translations had been attained from earlier projects and were controlled by independent, native speaking, interpreters before they were added to the questionnaire. The items appeared one after the other on the screen, together with answering alternatives. All text had a sound-file connected to it that started as soon as the item appeared on the screen. The test could be used with any level of reading competence, and the sound of each item could be activated by touch as many times as necessary. Items could be skipped and left unanswered, but would then be repeated once more towards the end of the questionnaire. The first introduction to the computer-based self-screening was done shortly after arrival, with one language group at the time. An interpreter was present together with maximum five participants, as they were instructed in how to use the touch screen. They were encouraged to ask clarifying questions as they went on with answering the items, all in the same room, with earphones on, in order not to disturb each other. During the following waves of data collection, the same questionnaire was used and translating services were not necessary. The results were transported digitally to the SPSS files.

\section{Data analysis}

Differences in HSCL and PTSS between 0, 4, 15 and 26 months were assessed by linear mixed effects models by categorical time, including an interindividual random effect. Relationships between HSCL and PTSS at each time point $\geq 4$ months and characteristics known at that time point were assessed by unadjusted and linear regression. Specifically, covariates were being literate, parents deceased, number of adverse events and age assessed as $\geq 18$ years at 4 months. At 15 months, being placed in a reception centre for adults or youth was included, and at 26 months also asylum status: permanent, time-limited or refusal of asylum. Due to a low number of missing values in the independent variables in the regression analyses (at most three missing values on any independent variable), complete case analysis was considered appropriate. Non-response analysis during follow-up (4-26 months) used a generalised estimating equations (GEE) logistic regression by time and baseline HSCL score, reading ability, category for parents alive and number of serious life events. For descriptive analyses, we used the SPSS Version 22 for Windows. Beyond this, data were analysed using R (The R Foundation for Statistical Computing, Vienna, Austria) with the $\mathrm{R}$ package nlme for mixed effects models and gee for GEE analyses. ${ }^{22}$

\section{Results}

Three-fourths of the population came from Afghanistan, while the remaining came from Somalia and Iran (table 1). There were no significant differences between the countries of origin and the variables included in this article. A minority (36\%) were able to read in their own language. Mean number of serious lifetime events experienced was 6.1 (SD 2.3), range 1-11. Most of the participants $(96 \%)$ had experienced at least one of the serious life events listed. The most frequently reported experiences were life-threatening events (82\%), physical abuse $(78 \%)$ and loss of a close relative $(78 \%)$. The official age assessment found a mean age of 18.4 years (SD 2.4 ), range $15-28$, which meant that 72 (56\%) participants were considered to be adults. Of this 'adult' group, 36 participants were allowed to stay at the care centres for adolescents, while the rest had to move to centres for adults. None of the participants received psychiatric treatment during the study. Overall, there were no significant changes in the level of symptoms within the study period ( $\mathrm{p} \geq 0.084$ ), neither for HSCL (table 2) nor for PTSS. 
Table 1 Baseline characteristics of male unaccompanied refugee minors at arrival in Norway

\begin{tabular}{lc}
\hline & $\mathbf{N}=138$ \\
\hline Age, self-reported $(\mathrm{n}=130)$ & \\
\hline Mean years (SD) & $16.22(0.84)$ \\
\hline Range & $14-20$ \\
\hline Age, assessed by authorities $(\mathrm{n}=132)$ & \\
\hline Mean years (SD) & $18.22(2.27)$ \\
\hline Range & $15-27$ \\
\hline Nationality & \\
\hline Afghan & $102(73.9)$ \\
\hline Somalian & $32(23.2)$ \\
\hline Iranian & $3(2.2)$ \\
\hline Algerian & $1(0.7)$ \\
\hline Literacy, self-reported $(n=136)$ & $50(36.8)$ \\
\hline No loss of parent & $30(21.7)$ \\
\hline Loss of father & $60(43.5)$ \\
\hline Loss of mother & $4(2.9)$ \\
\hline Loss of both parents & $25(18.5)$ \\
\hline Unknown & $16(11.9)$ \\
\hline Psychological distress $(n=131)$ & \\
\hline Mean HSCL $(S D)$ & $29(21.0)$ \\
\hline Caseness $(n \geq 2.0)$ & \\
\hline Caseness $(n \geq 2.0)$ & $(58.7)$ \\
\hline
\end{tabular}

Values are given as number (\%) when others not specified. HSCL, Hopkins Symptom Checklist; PTSS, Post-Traumatic Stress Symptom Checklist.

Tables 3-5 show the associations between variables of interest and symptoms of psychological distress at different test points. Outcome of age assessment, which was known shortly after the first assessment, had no significant association with psychological distress at 4 months (table 3). However, those who were estimated to be 18 years or older, had higher levels of symptoms at 15 months (table 4) and at 26 months (table 5), but not when adjusted for the outcome of the asylum applications at the 26-month assessment.
One-third of the participants were placed in a reception centre for adults. Figure 1 shows the trajectories of psychological distress for participants placed in a reception centre for adults or for youth. Those who were placed in a reception centre for adults had higher levels of psychological distress symptoms both at 15 months (table 4) and 26 months (table 5) compared with the remaining participants who were placed in reception centres for youth. However, when adjusted for the outcome of the asylum application at the 26-month assessment, the difference was not significant.

Final decision on the asylum claims was given between the last two test points. Refusal was highly associated with higher levels of psychological distress. Achieving time-limited residence permission was not significantly different compared with permanent asylum (table 5). Trajectories of psychological distress for those who received refusal or acceptance of their asylum application are illustrated graphically in figure 2. Refusal was related to the official determined age of the asylum seeker. Among the participants who were considered to be 18 or more, 52 out of $72(72.2 \%)$ were refused, compared with 15 out of 59 (25.4\%) among the participants who were considered to be under 18 (seven missing).

The symptom scores of the PTSS (not illustrated in the tables) showed a similar association as the HSCL scores, with higher levels of PTSD symptoms for those placed in a reception centre for adults at 15 months (adjusted difference $0.34,95 \%$ CI 0.06 to $0.63, \mathrm{p}=0.017$ ) as well as higher symptom scores for those who received a negative result for the asylum application at 26 months (adjusted difference $0.60,95 \%$ CI 0.24 to $0.95, p=0.001$ ).

Loss to follow-up was not significantly related to initial levels of distress. Also, none of the baseline covariates were significantly related to non-response.

\section{DISCUSSION}

The present study is a follow-up of unaccompanied refugee minors with four waves of assessment from within 3 weeks after arrival to more than 2 years spent in the host country. At the group level, the young asylum seekers reported high levels of psychological distress on arrival and symptom levels that stayed relatively unchanged over time. A low level of support during the asylum process and a negative outcome of the asylum

Table 2 MEC for time modelling the course of psychological distress (HSCL) and post-traumatic stress (PTSS) in unaccompanied refugee minors after arrival in host country

\begin{tabular}{|c|c|c|c|c|c|c|}
\hline & \multicolumn{3}{|c|}{ HSCL } & \multicolumn{3}{|c|}{ PTSS } \\
\hline & MEC & $95 \% \mathrm{Cl}$ & p Value & MEC & $95 \% \mathrm{Cl}$ & p Value \\
\hline Time & & & 0.136 & & & 0.725 \\
\hline 15 months versus 0 months & 0.14 & 0.01 to 0.27 & 0.037 & 0.03 & -0.11 to 0.17 & 0.671 \\
\hline 26 months versus 0 months & -0.02 & -0.16 to 0.13 & 0.831 & -0.06 & -0.21 to 0.09 & 0.441 \\
\hline
\end{tabular}

HSCL, Hopkins Symptom Checklist; MEC, mixed effect coefficients; PTSS, Post-Traumatic Stress Symptom Checklist. 
Table 3 Regression coefficients for literacy, premigration bereavement, serious life events and postmigration age assessment, related to course of psychological distress (Hopkins Symptom Checklist) in young male asylum seekers 4 months after arrival in host country; results unadjusted and adjusted for the other variables

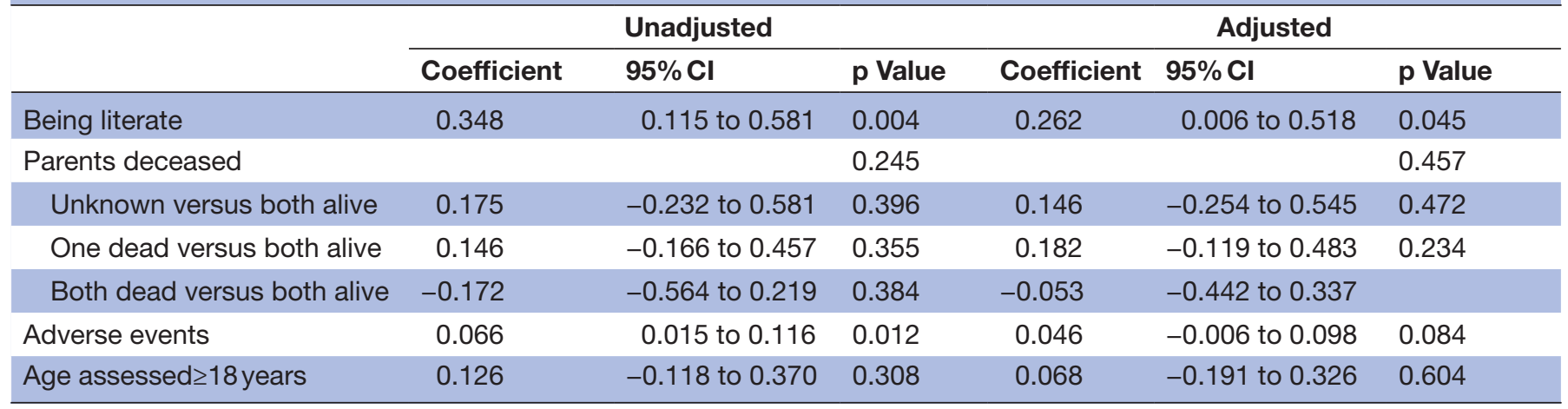

application were associated with higher levels of psychological distress.

Determination of the legal status of the asylum seekers involved age assessment procedures, with X-rays and dental examinations for all participants in this study. This resulted in a considerable gap between self-reported age and the official age estimates designated by the immigration authorities. On the basis of these examinations, $55 \%$ of the asylum seekers were considered to be at least the age of 18 and thus did not achieve a UM status. They risked being moved to a facility for adults, with low levels of support and care, and limited access to education and leisure activities. Also, the likelihood of being granted asylum was related to age, as illustrated by the numbers of children and adults in our study who got refusal of their claims.

The results from our study are in agreement with other studies that have found that high-support housing, with sufficient supervision, was associated with lower levels of psychological symptoms. ${ }^{5}$ Others have also described problems directly connected to the asylum process and have registered them as components in a list of postmigration stressors. ${ }^{9}$ A weakness with most of these studies, are cross-sectional designs where there are no baseline measurements. Only a few studies have repeated assessments ${ }^{6}$ where problems directly connected to the asylum process, such as age-assessment procedures, lack of adequate housing, low support, and so on, have been evaluated. The complexity of factors contributing to the increasing health risk make it difficult to draw specific conclusions within the total burden of stressors.

In all studies with UM, it is likely that there will be some uncertainty concerning the participants' true chronological age. ${ }^{3}$ Defined to be overage, in the present study, was not significantly related to the symptom scores at the 4-month assessment, and there was no indication that this process was stressful in itself. The age designated by the authorities, determined what type of housing and level of care that was offered during the remaining asylum procedure. This meant that many of the participants had to live in a reception centre for adults, where they had no guardian, no school, had to cook for themselves and budget their benefits. Our findings that this group had higher levels of psychological distress add further evidence that living conditions in the asylum seeking period may influence the mental health of young refugees. ${ }^{69}$ It was probably known in the community and among the youth that being categorised as an adult increased the risk of asylum refusal. This factor is impossible to separate from the expectations associated with the placement in youth

Table 4 Regression coefficients for literacy, premigration bereavement, serious life events and postmigration age assessment, in addition to asylum seeker facilities, related to course of psychological distress (Hopkins Symptom Checklist) in young male asylum seekers 15 months after arrival in host country; results unadjusted and adjusted for the other variables

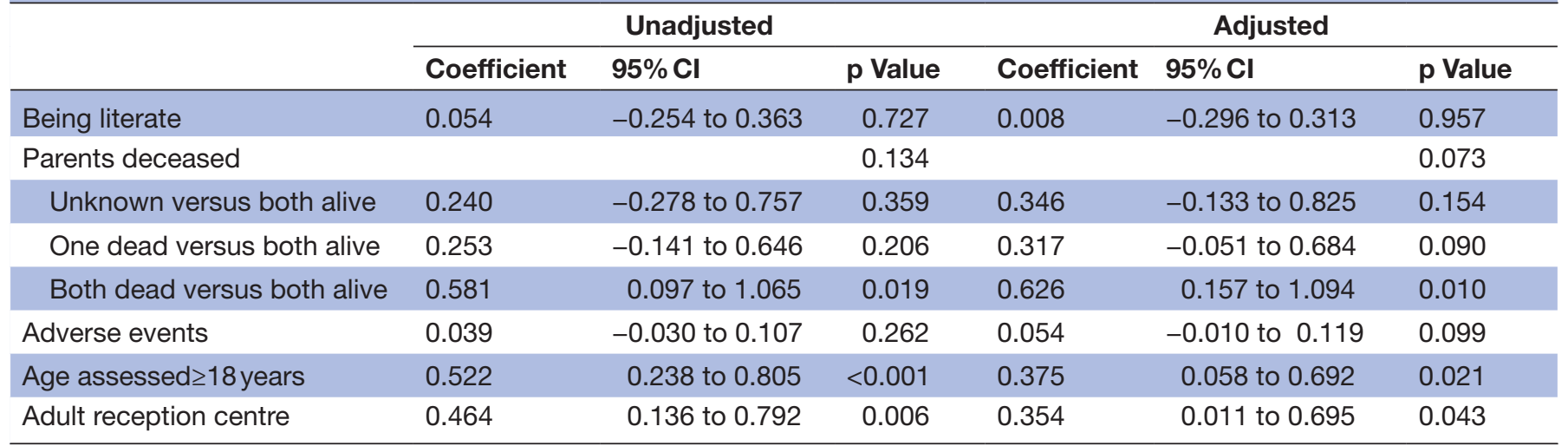


Table 5 Regression coefficients for literacy, premigration bereavement, serious life events and postmigration age assessment, asylum seeker facilities, in addition to asylum status, related to course of psychological distress (Hopkins Symptom Checklist) in young male asylum seekers 26 months after arrival in host country; results unadjusted and adjusted for the other variables

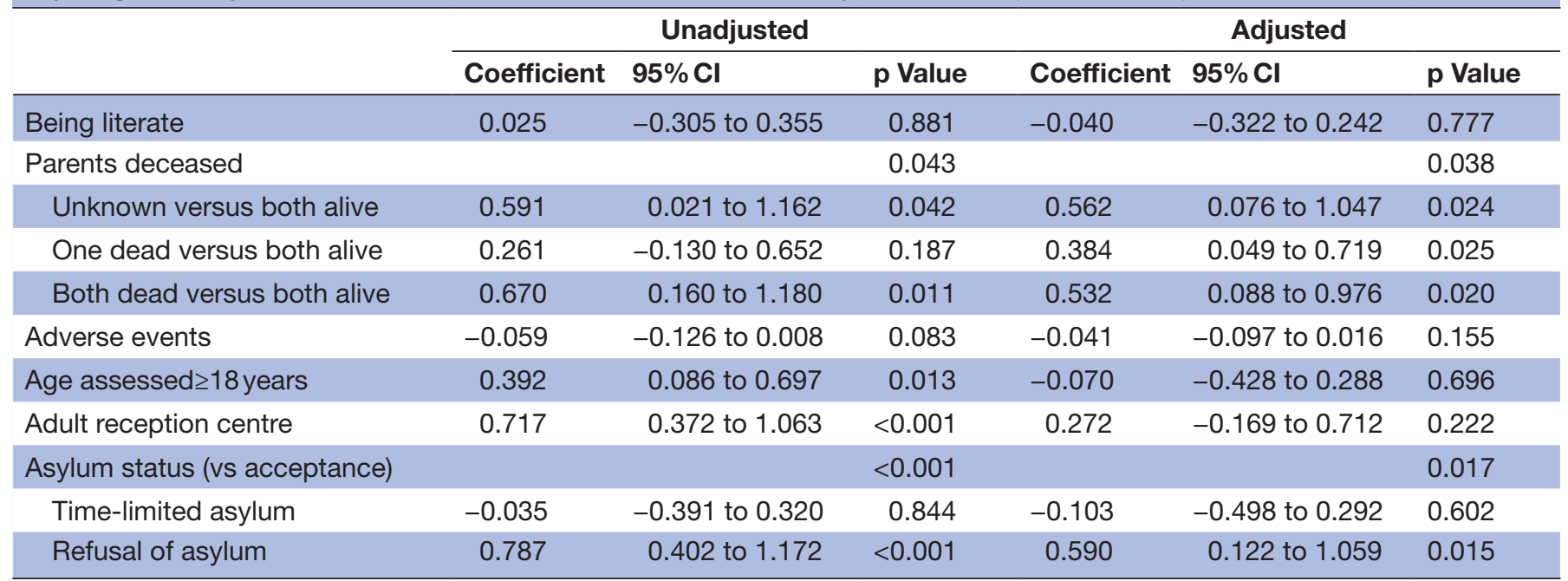

or adult reception centres. There should be a cautious interpretation of the results because of this clustering of risk factors. It is also possible that the asylum interviews were more adversarial for those who had adverse age assessments. These interviews happened early in the asylum trajectories, but these official age assessments may have been used to question testimonial credibility in the asylum process.

The outcome of the individual asylum applications was revealed to the asylum seekers between 1 and 2 years after the arrival, and the negative impact of refusal was as expected since several studies have found that difficulties obtaining legal residence are associated with a range of psychological problems for this group. ${ }^{6}$ We also know that longitudinal

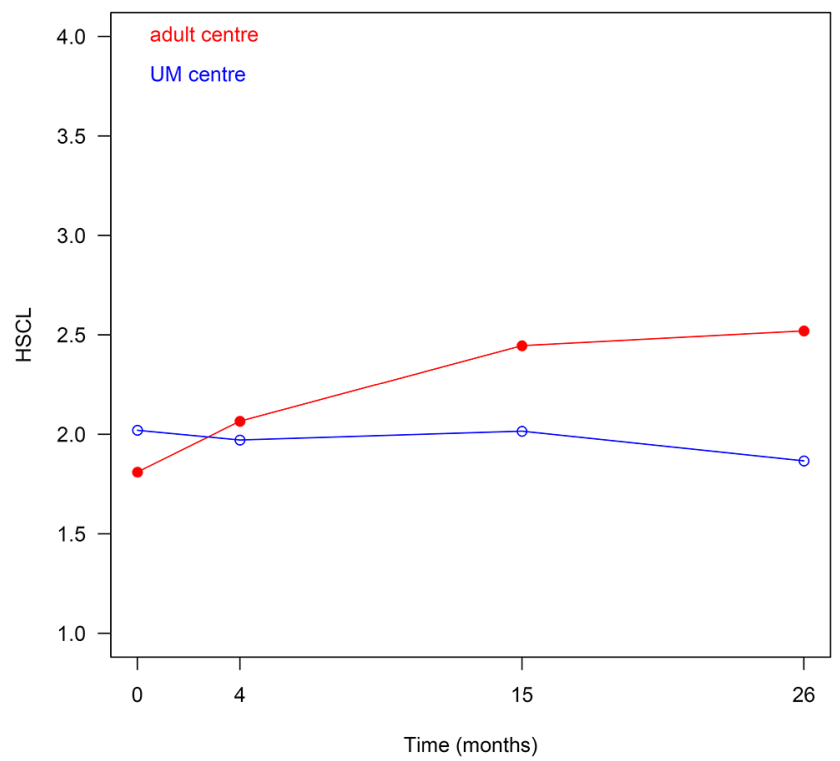

Figure 1 Course of psychological distress (Hopkins Symptom Checklist (HSCL)) during follow-up of asylum seekers placed in asylum centres for adults $(n=38)$ and asylum seekers placed in asylum centres for youth $(n=100)$. studies indicate a trend towards reduction of mental health symptoms for resettled refugees over time. ${ }^{23}$ In a follow-up study of 131 young refugees in Denmark, the long-term effects of premigration adversity were mediated by a variety of factors connected to social life. ${ }^{24}$ Another study suggests positive health effects on receiving permanent residence mediated through improved living conditions. ${ }^{25}$ This, in association with our findings, emphasises the importance of a supportive postmigration environment for all refugees with premigratory experiences of serious trauma and human rights violations.

Strengths of our study include a longitudinal design, with first assessment within 3 weeks after arrival to the host

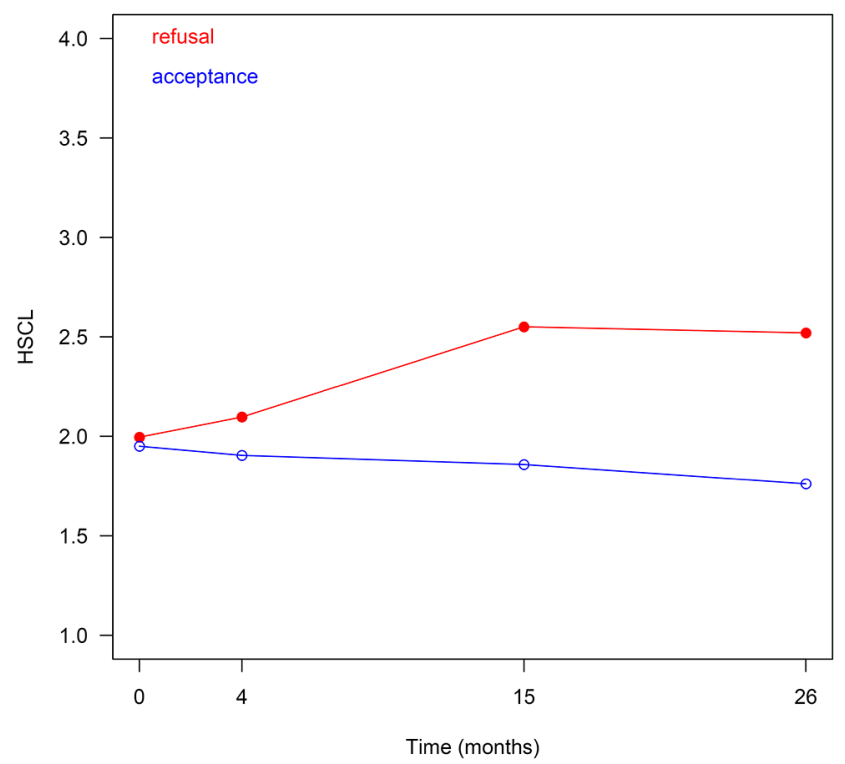

Figure 2 Course of psychological distress (Hopkins Symptom Checklist (HSCL)) during follow-up of asylum seekers who received refusal of asylum $(n=67)$ and asylum seekers who received residence permission or time-limited asylum $(n=64)$. 
country and repeated measures. We used computer-based assessment with the same audio-translations throughout the study and did not need to use interpreters in order to complete the psychometric measures at follow-up. Due to a random selection of participants, we consider the sample to be representative for the refugees arriving to Norway in the beginning of the century. However, selection of participants was limited to the most common nationality groups arriving in Norway in this period and may limit the generalisation of our findings to refugees in general.

High attrition rate due to the fact that asylum seekers tend to move between and within countries, and that many were told to leave the country, may have biased our findings. It is also possible that our research team was not viewed as independent from the authorities, even though we stressed this fact when we informed about the project. Finally, we have no data as to whether poor mental health might have affected the likelihood of asylum. Mental health is generally not an issue in the processing of asylum applications in Norway. Also, the baseline levels of mental health did not differ between participants that later received asylum and those who did not.

\section{Implications}

Our study shows that young asylum seekers may spend considerable time in a safe Western country, without recovering from the distress they have when they arrive in the host country. A reason for the continuing psychological health problems in this non-clinical group of youth can possibly be found in the living conditions and the level of care that is provided.

Adolescence is a challenging transition period for most people. Fleeing to a foreign country without parents or other caregivers makes this life period even more challenging for young refugees and puts a considerable responsibility on the receiving countries. The burden of increasing numbers of asylum seekers challenges the political intentions of the UN Convention on the Rights of the Child to always give precedence to 'the best interest of the child'. ${ }^{26}$ It is emphasised that safety and dignity in the use of medical assessments should be applied as a supplement to evaluations of the physical appearance and the psychological maturity of the child.

An important objection to the use of dental/bone-age assessments is their lack of precision, especially around the time of puberty. The tests have been criticised for their large margins of error and their inadequacy in determining chronological age. ${ }^{3}$ Professionals in various countries have differed with some doctors refusing to take part in such tests, while others have argued that these assessments are the best practice available.

Needs of vulnerable adolescents and young adults in a stressful life situation deserve high priority and should be a main focus regardless of the outcome of age assessments. ${ }^{27}$ It is noteworthy that access to psychiatric care was not evident for any of the participants although a majority of this sample had symptom levels suggesting a positive diagnosis of PTSD. This may reflect a lack of resources available for this population or reluctance to ask for healthcare.

In our society, turning 18 is usually considered a transition point from child to adult. Yet with the limitations of the age-determining process, we cannot know for certain that this milestone has been reached. The consequences of this uncertainty can have legal, social and material implications. ${ }^{28}$ If a child is put under difficult living conditions, where previous human support and education are withdrawn, this can have unintended negative effects on these young individuals transitioning into adulthood. Some child protection services argue that vulnerable young adults are still in need of support and care after the age of $18^{29}$ and need to receive specialised care into their 20s. ${ }^{30}$ Future studies should focus on how mental health and resilience evolve over a longer time span and evaluate specific interventions and appropriate levels of care for young refugees.

Correction notice This paper has been amended since it was published Online First. Owing to a scripting error, some of the publisher names in the references were replaced with 'BMJ Publishing Group'. This only affected the full text version, not the PDF. We have since corrected theseerrors and the correct publishers have been inserted into the references.

Acknowledgements Gratitude to Liv Berit Løken for her care and assistance with all aspects of data collection. Thanks also to our very skilled interpreters and to all the young participants.

Contributors MJ has had the main responsibility for the drafting and writing of the article. TH was, in collaboration with MAMD and MJ, responsible for the literature review and the conception and design of the article. MAMD and MJ have been responsible for all phases of the data collection. Data analysis and interpretation of data were done in cooperation among MJ, TH and TW-L. All authors have contributed to the scientific writing and proof-reading of the article. The paper has been read and approved by all authors before submission.

Funding This work was supported by the Norwegian Directorate of Immigration. Competing interests None declared.

Patient consent Obtained.

Ethics approval The Regional Medical Ethics Committee, South-East Norway approved this study.

Provenance and peer review Not commissioned; externally peer reviewed.

Data sharing statement № additional data are available.

Open Access This is an 0pen Access article distributed in accordance with the Creative Commons Attribution Non Commercial (CC BY-NC 4.0) license, which permits others to distribute, remix, adapt, build upon this work non-commercially, and license their derivative works on different terms, provided the original work is properly cited and the use is non-commercial. See: http://creativecommons.org/ licenses/by-nc/4.0/

(c) Article author(s) (or their employer(s) unless otherwise stated in the text of the article) 2017. All rights reserved. No commercial use is permitted unless otherwise expressly granted.

\section{REFERENCES}

1. Statistics explained. Asylum Statistics. Eurostat. 2016. http://ec. europa.eu/eorostat/statistics-explained/index.php/Asylum_statistics. (retrieved 02 May 2016).

2. Evans R, Forte CL, Fraser EM. UNHCR's engagement with displaced youth: a global review. UNHCR, 2013.

3. Hjern A, Brendler-Lindqvist M, Norredam M. Age assessment of young asylum seekers. Acta Paediatr 2012;101:4-7.

4. Huemer J, Karnik NS, Voelkl-Kernstock S, et al. Mental health issues in unaccompanied refugee minors. Child Adolesc Psychiatry Ment Health 2009;3:13. 
5. Bean T, Derluyn I, Eurelings-Bontekoe E, et al. Comparing psychological distress, traumatic stress reactions, and experiences of unaccompanied refugee minors with experiences of adolescents accompanied by parents. J Nerv Ment Dis 2007;195:288-97.

6. Hodes M, Jagdev D, Chandra N, et al. Risk and resilience for psychological distress amongst unaccompanied asylum seeking adolescents. J Child Psychol Psychiatry 2008;49:723-32.

7. Senovilla Hernández D. Unaccompanied children lacking protection in Europe. Final comparative report. PUCAFREU, 2013.

8. Silove D, Steel Z, Susljik I, et al. The impact of the refugee decision on the trajectory of PTSD, anxiety, and depressive symptoms among asylum seekers: a longitudinal study. Am J Disaster Med 2007:2:321-9.

9. Vervliet M, Lammertyn J, Broekaert E, et al. Longitudinal follow-up of the mental health of unaccompanied refugee minors. Eur Child Adolesc Psychiatry 2014;23:337-46.

10. A longitudinal study of mental health in unaccompanied refugee minors during the asylum process and early intervention with expressive arts therapy (EXIT) for newly arrived unaccompanied minor refugee boys in transit centers. https://www.nkvts.no/english/ project/expressive-arts-therapy-for-newly-arrived-unaccompaniedminor-refugee-boys-in-transit-centers/.

11. Bean T, Eurelings-Bontekoe E, Derluyn I, et al. Stressful life events (SLE): user'smanual. Centrum' 2004;45.

12. Mollica RF, McDonald LS, Massagli MP, et al. Measuring trauma, measuring torture: instructions and guidance on the utilization of the Harvard Program in Refugee Trauma's versions of the Hopkins Symptom Checklist- 25 (HSCL-25) and The Harvard Trauma Questionnaire (HTQ). Harvard Program in Refugee Trauma, 2004.

13. Hollifield $\mathrm{M}$, Warner TD, Lian N, et al. Measuring trauma and health status in refugees: a critical review. JAMA 2002;288:611-21.

14. Silove D, Manicavasagar V, Mollica R, et al. Screening for depression and PTSD in a cambodian population unaffected by war: comparing the hopkins symptom checklist and harvard trauma questionnaire with the structured clinical interview. J Nerv Ment Dis 2007;195:152-7.

15. Bronstein I, Montgomery P, Ott E. Emotional and behavioural problems amongst Afghan unaccompanied asylum-seeking children: results from a large-scale cross-sectional study. Eur Child Adolesc Psychiatry 2013;22:285-94.
16. Bean T, Eurelings-Bontekoe E, Derluyn I, et al. Hopkins Symptom Checklist-37 for Adolescents (Hscl-37a): User's Manual. In: Centrum 45. Oegstgeest, 2004.

17. Jakobsen M, Meyer DeMott MA, Heir T. Validity of screening for psychiatric disorders in unaccompanied minor asylum seekers. use of computer-based assessment. Transcultural Psychiatry In Press. 2016.

18. Mollica RF, Caspi-Yavin Y, Bollini P, et al. The Harvard Trauma Questionnaire. Validating a cross-cultural instrument for measuring torture, trauma, and posttraumatic stress disorder in Indochinese refugees. J Nerv Ment Dis 1992;180:111-6.

19. Jones L, Kafetsios K. Exposure to political violence and psychological Well-being in bosnian adolescents: a mixed method approach. Clin Child Psychol Psychiatry 2005;10:157-76.

20. American Psychiatric Association. Diagnostic and statistical manual of mental disorders 4th ed (DSM-IV). APA, 1994.

21. Knaevelsrud C, MultiCASI MJ. MultiCASI (Multilingual Computer Assisted Self Interview). Springer, 2008. CD-ROM, CDSP.

22. Pinheiro J, Bates D, DebRoy S, et al. NIme: Linear and Nonlinear MixedEffects Models. R package version 3.1-128. 2016. http:// CRAN.R-project.org/package $=$ nlme $>$.

23. Fazel M, Reed RV, Panter-Brick C, et al. Mental health of displaced and refugee children resettled in high-income countries: risk and protective factors. Lancet 2012;379:266-82.

24. Montgomery E. Trauma and resilience in young refugees: a 9-year follow-up study. Dev Psychopathol 2010;22:477-89.

25. Lamkaddem M, Essink-Bot ML, Devillé W, et al. Health changes of refugees from Afghanistan, Iran and Somalia: the role of residence status and experienced living difficulties in the resettlement process. Eur J Public Health 2015;25:917-22.

26. Vitus K, Liden $\mathrm{H}$. The status of the asylum-seeking child in Norway and Denmark: comparing discourses, politics and practices. J Refug Stud 2010;23:62-81.

27. Derluyn I, Broekaert E. Unaccompanied refugee children and adolescents: the glaring contrast between a legal and a psychological perspective. Int J Law Psychiatry 2008;31:319-30.

28. Smith T, Brownlees L. Age assessment practices: a literature review \& annotated bibliography. Discussion paper. UNICEF, 2011.

29. Crawley H. When is a child not a child. ILPA, 2007.

30. Courtney ME, Piliavin I, Grogan-Kaylor A, et al. Foster youth transitions to adulthood: a longitudinal view of youth leaving care. Child Welfare 2001;80:685-717. 